\title{
Enzymatic coating of jute fabrics for enhancing anti-ultraviolent properties via in-situ polymerization of polyhydric phenols
}

\section{Aixue Dong', Yuanyuan Yu', Xuerong Fan ${ }^{1,2}$, Qiang Wang ${ }^{1,2}$ and Artur Cavaco-Paulo ${ }^{2,3}$}

\begin{abstract}
To enhance the anti-ultraviolent properties of technical jute fabrics, the enzymatic surface coating with the in-situ produced phenolic polymers of polyhydric phenols was investigated in this study. Firstly, the laccase-mediated polymerization of the five polyhydric phenols (catechol, resorcinol, hydroquinone, pyrogallol and phloroglucinol) was analyzed by FT-IR. Catechol and pyrogallol were polymerized together by laccase with ether bonds linked. On the contrary, the units of resorcinol, hydroquinone and phloroglucinol in their enzymatically formed polymers concatenated to each other by C-C bonds. Then, the coated jute fabrics were characterized in terms of $X$-ray photoelectron spectroscopy and scanning electron microscopy. The increasing of the $\mathrm{C} / \mathrm{O}$ ratio on the jute fabric surface after the coating treatments supported the achievement of the enzymatic coating on jute fabrics via the in-situ polymerization of phenolic compounds and the grafting reaction of polyphenols with lignins on the surface. The sequence of the coating extent by using various polyhydric phenols was proved to be catechol, pyrogallol, resorcinol, phloroglucinol and hydroquinone in order from rich to poor according to the O-C-O component of cellulose in the $\mathrm{Cls}$ spectra of jute fabrics and the
\end{abstract}

\footnotetext{
'Key Laboratory of Science and Technology of Eco-Textiles, Ministry of Education, Jiangnan University, Wuxi, Jiangsu, PR China

${ }^{2}$ International Joint Research Laboratory for Textile and Fiber Bioprocesses, Jiangnan University, Wuxi, Jiangsu, China

${ }^{3}$ Department of Biological Engineering, University of Minho, Campus de Gualtar, Braga, Portugal
}

\section{Corresponding author:}

Qiang Wang, Key Laboratory of Science and Technology of Eco-Textiles, Ministry of Education and International Joint Research Laboratory for Textile and Fiber Bioprocesses, Jiangnan University, Wuxi, 214122, Jiangsu, China.

Email: qiang_wang@।63.com 
scanning electron microscopy photographs of jute surfaces. Lastly, the ultraviolent protection factor and the ultraviolent resistance of the coated jute fabrics were measured. The ultraviolent protective performance of jute fabrics after the coating treatments depended both on the coating amount and the chemical structure of the coated polymers. Among the tested polyhydric phenols, the polymerization of catechol obtained the best coating for ultraviolent protection. Different polyhydric phenols employed for the enzymatic coating showed different trends in ultraviolent protection factor of jute fabrics with the increasing of incubation time. The jute fabrics coated with in-situgenerated polycatechols or polyresorcinols had excellent ultraviolent resistances.

\section{Keywords}

Jute, coating, ultraviolent protection, polyphenols, laccase, grafting

\section{Introduction}

In recent decades, the destruction of ozone layer in air due to wanton discharge of chlorofluorocarbons in production and living has gained wide concern. Nowadays, the surface of earth receives more ultraviolent (UV) rays than that in the past. As a consequence, human beings as well as lifeless substrates are suffering more challenges of UV radiation. Despite the elimination of air pollution has to be carried out, textiles with UV protective properties are also needed for preventing human beings or vulnerable materials from UV lights [1-6].

Jute fiber is a widely used textile material in home and industry [7-9]. Jute fabrics can be utilized in technical textiles outdoors, such as packing bags, ropes and textile coverings. The anti-UV performance of jute products can enhance their working life and maintain the mechanical properties for a longer time under sun light. In order to increase the UV resistance of technical jute textiles, chemical modifications including surface coating have been employed generally [10-13]. Nowadays, the use of enzymes as important biotechnological catalysts has emerged in the processing of lignocellulosic polymers [14-19]. Enzymatic processes have numerous advantages such as specificity, low cost to effectness, eco-friendly nature and working in mild conditions as compared to the conventional methods. Laccases (EC 1.10.3.2, benzenediol: oxygen oxidoreductase) are multi-copper-containing zymoproteins that catalyze the mono-electronic oxidation of phenols or aromatic amines to reactive radical species and simultaneously reduce molecular oxygen to water in a redox reaction [20]. Lignin is a threedimensional aromatic polymer with three structural units including guaiacyl, syringyl and p-hydroxyphenyl jointed together in an irregular manner [21]. Researches show that lignin is a suitable substrate for laccase and the phenolic sites of lignin molecules can be oxidized to phenoxyl radicals by laccase [22,23]. With the laccase-catalyzed oxidation of lignin moieties rich on the surface, the lignocellulosic materials could be activated to create a radical-rich reactive surface to which oxidized (radical-containing) phenolic molecules by laccase 
simultaneously can be grafted [24-30]. Jute fiber with lignin content of $14 \%-20 \%$ also has the potential to be modified by this green biotechnology for endowing it with better performance or new functions.

According to the literature [31], phenolic compounds with low molecular weight could be polymerized to macromolecules by the oxidative catalysis of laccase. With the involvement of jute fabrics in the reaction, however, the coupling of the in-situproduced polyphenol chains to lignin moieties on the jute surface or the initiation of the grafting copolymerization with phenolic monomers at the lignin-containing surface sites should occur. Simultaneously, the generated homopolymers could also deposit onto the jute surface and combine with the grafted polymers or jute surface by hydrogen bonds to form a new surface coating. Thus, this novel laccase-facilitated coating with the synergy of covalent coupling/grafting and non-covalent deposition will lead to strong binding bond onto the jute surface compared with conventional depositions [32]. Among the various phenolic compounds, polyhydric phenols such as catechol and pyrogallol have higher redox potentials for laccase and could be easily oxidized and polymerized with higher polymeric degree [33]. The corresponding polymerized coating which carries tremendous phenyl groups would show strong anti-UV properties and could further protect the jute fabrics from UV rays. However, as far as our knowledge goes, this kind of polyphenolbased UV protection of textiles has not been made before.

In this work, the laccase-mediated polymerization of five polyhydric phenols (catechol, resorcinol, hydroquinone, pyrogallol and phloroglucinol) and the insitu coating with produced polyphenols for improving the UV protection of industrial jute fabrics were investigated, as presented in Figure 1. Initially, the chemical structures of the enzymatically produced phenolic polymers were analyzed by FT-IR in comparison with their corresponding phenolic monomers. Then, the
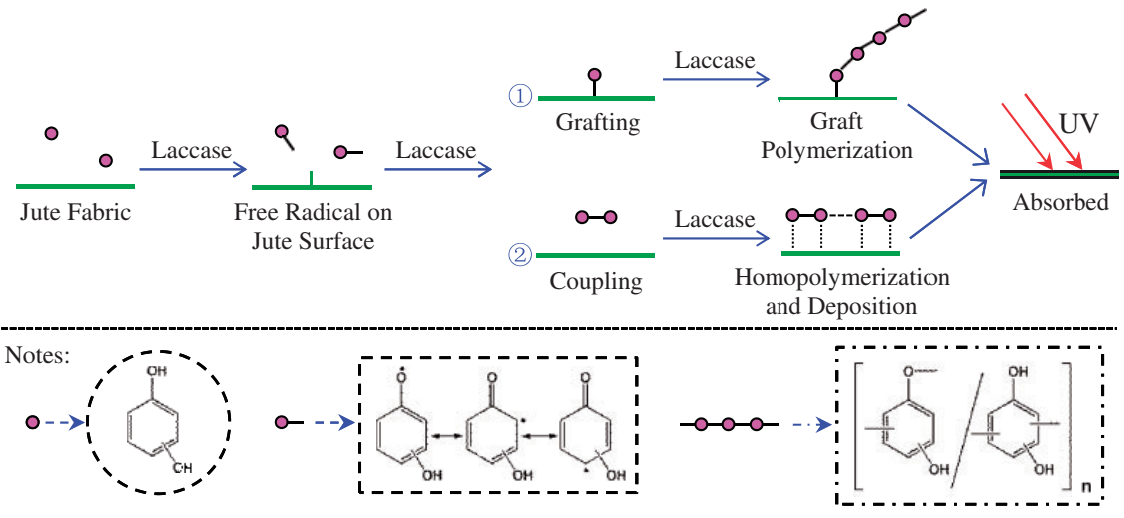

Polyhydric Phenol Free Radical of Polyhydric Phenol

Polymer of Polyhyidric Phenol

Figure I. Schematic illustration of the enzymatic coating of jute fabrics for enhancing anti-UV properties via in-situ polymerization of polyhydric phenols. 
surfaces of jute fabrics coated by various polyhydric phenols were characterized in terms of X-ray photoelectron spectroscopy (XPS) and scanning electron microscopy (SEM). Further, the ultraviolent protection factor (UPF) and the UV resistance of jute fabrics after the coating treatments with different incubation periods were determined.

\section{Materials and methods}

\section{Materials}

Laccase from Trametes Versicolor was provided by Sigma-Aldrich. The 100\% raw jute fabric $\left(427 \mathrm{~g} / \mathrm{m}^{2}\right)$, with a $7 / 7$ (warp $/$ weft) $\mathrm{cm}^{-1}$ fabric density, was supplied by Longtai weaving Co., Ltd (Changshu, China). Five polyhydric phenols including catechol, resorcinol, hydroquinone, pyrogallol and phloroglucinol were all commercially available and were of analytical purity.

\section{Laccase assay}

The activity of laccase was determined using a UV/Vis spectrophotometer by monitoring the oxidation of 2, 2'-azino-bis-(3-ethylthiazoline-6-sulfonate) (ABTS; $\varepsilon_{420}=36,000 \mathrm{M}^{-1} \times \mathrm{cm}^{-1}$ ) as substrate at $420 \mathrm{~nm}$ in $0.2 \mathrm{mM}$ acetate buffer $(\mathrm{pH} 4)$ at $50^{\circ} \mathrm{C}$. The enzyme activity was expressed in units defined as micromoles of ABTS oxidized per minute [34].

\section{Enzymatic oxidative polymerization of polyhydric phenols}

Each polyhydric phenol (catechol, resorcinol, hydroquinone, pyrogallol and phloroglucinol) of $40 \mathrm{mM}$ was incubated in $0.2 \mathrm{M}$ acetate buffer $(\mathrm{pH} 4)$ with $2.5 \mathrm{U} / \mathrm{mL}$ laccase. The reaction was carried out at $50^{\circ} \mathrm{C}$ for $36 \mathrm{~h}$ in a shaking bath with a speed of $30 \mathrm{r} / \mathrm{min}$. Then the reaction solution was centrifuged and the precipitates were washed with distilled water twice to obtain the polyphenols.

\section{FT-IR analysis of polyphenols}

The FT-IR analysis of the polyphenols obtained above was performed using a Nicolet iS10 FT-IR spectrometer (Thermo Fisher Scientific, USA) with the $\mathrm{KBr}$ pellet technique. The spectra were recorded in the range of $4000-650 \mathrm{~cm}^{-1}$ at $4 \mathrm{~cm}^{-1}$ resolution and 16 scans per sample.

\section{Jute fabric preparation}

The jute fabrics were Soxhlet-extracted with benzene/ethanol (v:v, 2:1) for $12 \mathrm{~h}$ to remove lipophilic extractives and then boiled with distilled water for $3 \mathrm{~h}$ to remove 
water-soluble fractions. As a result, the oxidation of substrate molecules by laccase and the analysis of modified fabrics could be carried out without interference.

\section{Enzymatic coating of jute fabrics by in-situ polymerization}

Jute fabrics of $1 \mathrm{~g}$ were incubated in $50 \mathrm{~mL}$ acetate buffer $(\mathrm{pH} 4,0.2 \mathrm{M})$ with $2.5 \mathrm{U} /$ $\mathrm{mL}$ laccase and $40 \mathrm{mM}$ phenolic monomer at a shaking bath of $50^{\circ} \mathrm{C}$ for $36 \mathrm{~h}$. Afterwards, the fabrics were washed with distilled water at $50^{\circ} \mathrm{C}$ for $20 \mathrm{~min}$ twice. Control sample and the laccase-treated sample followed the same treatment condition as mentioned above.

\section{XPS analysis of jute fabrics}

XPS experiments were carried out using an Amicus spectrophotometer (Kratos Analytical Ltd., UK) with $\mathrm{Mg} \mathrm{K} \alpha$ radiation. The X-ray anode was run at $180 \mathrm{~W}$ and the high voltage was kept at $12.0 \mathrm{kV}$. The pass energy was fixed at $75 \mathrm{eV}$ to ensure sufficient resolution and sensitivity. The base pressure of the analyzer chamber was about $1 \times 10^{-6} \mathrm{~Pa}$. The sample was directly pressed to a self-supported disk $(10 \times 10 \mathrm{~mm})$ and mounted on a sample holder then transferred into the analyzer chamber. The whole spectra $(0-1100 \mathrm{eV})$ and the narrow spectra of carbon, oxygen and nitrogen with much high resolution were both recorded. Binding energies were calibrated with the containment carbon $(\mathrm{C} 1 \mathrm{~s}=284.6 \mathrm{eV})$. The spectrum analysis including background subtraction, deconvolution, integration and quantitation was carried out by using the XPS Peak4.1 software.

\section{SEM analysis of jute fabrics}

The jute fabric samples were scanned using a SU1510 SEM (Hitachi, Japan) under $5.00 \mathrm{k}$ voltages at $1.00 \mathrm{k}$ magnification.

\section{UPF measurement of jute fabrics}

The UPF of control, laccase-treated and various coated jute fabric samples with incubation time of $12 \mathrm{~h}, 24 \mathrm{~h}, 36 \mathrm{~h}, 48 \mathrm{~h}$ and $60 \mathrm{~h}$ was determined on a UV transmittance analyzer UV-1000F (Labsphere Co., USA). The detective wavelength ranged from $450 \mathrm{~nm}$ to $250 \mathrm{~nm}$. For each fabric sample, four spots were measured and the results were averaged. For each treatment, quintuplicate samples were measured.

\section{UV resistance measurement of jute fabrics}

Jute samples incubated for $36 \mathrm{~h}$ were exposed to UV rays at $0.89 \mathrm{~W} / \mathrm{m}^{2}$ for $8 \mathrm{~h}$ in an accelerated UV-aging tester QUV/SPRAY (Q-Lab Co., USA). Then the UPF of 
the irradiated fabrics was determined and compared with that of the samples before irradiation.

\section{Results and discussion}

\section{FT-IR analysis of polyphenols}

To estimate the structural characteristics of the five polyhydric phenols and their laccase-induced polymeric products, corresponding FT-IR spectra were measured and are presented in Figure 2. The peaks from 3500 to $3200 \mathrm{~cm}^{-1}$ in the IR spectra of all samples belonged to the phenolic O-H vibrations. Bands between 1650 and $1400 \mathrm{~cm}^{-1}$ represented the aromatic skeletal vibrations. The peaks at 1300 $1000 \mathrm{~cm}^{-1}$ and $900-650 \mathrm{~cm}^{-1}$ were contributed to the C-O stretching vibrations and the $\mathrm{C}-\mathrm{H}$ out-of-plane bending vibrations in aromatic rings, respectively. In contrast to the phenolic monomers, the phenolic $\mathrm{O}-\mathrm{H}$ vibration peaks of polyphenols became broader due to the intramolecular hydrogen bonding between the repeating units in polyphenol chains [35]. In addition, the absorption bands of the polymeric structures between 1600 and $650 \mathrm{~cm}^{-1}$ were weakened, which can be ascribed to the more rigid groups in the polymers when compared to the monomer molecules [35]. Meanwhile, the steric hindrance of the macromolecular polymers produced by the laccase-mediated polymerization might also hinder the detection of these groups [36].
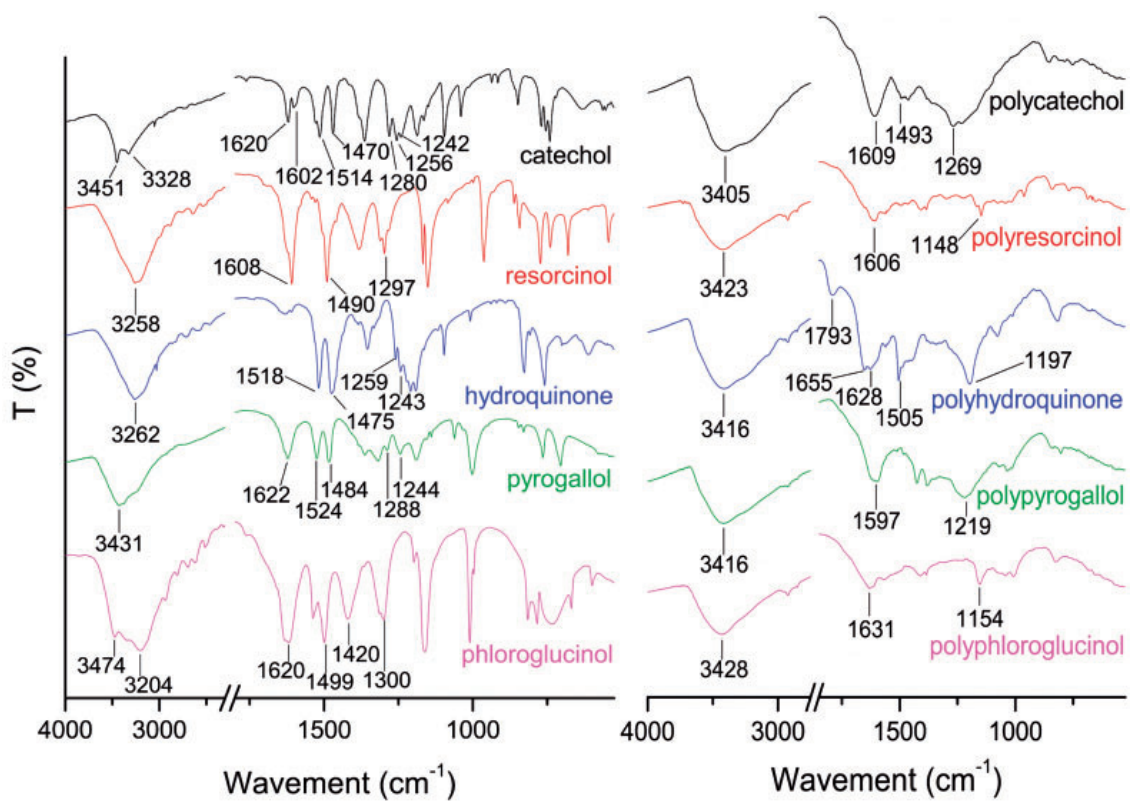

Figure 2. FT-IR spectra of the five polyhydric phenols and their corresponding polymers. 
For catechol, the characteristic doublet peaks at $3451 \mathrm{~cm}^{-1}$ and $3328 \mathrm{~cm}^{-1}$ represented the vibrations of its phenolic ortho-hydroxyl structure. On the contrary, the phenolic O-H adsorption bands of polycatechol appeared as one broad peak at $3405 \mathrm{~cm}^{-1}$. This variation can be mainly explained that the hydroxyl groups in catechol monomers were involved into the laccase-mediated oxidative polymerization. Four peaks of catechol at 1620, 1602, 1514 and $1470 \mathrm{~cm}^{-1}$ belonged to the aromatic $\mathrm{C}=\mathrm{C}$ vibration, while the peaks at $1609 \mathrm{~cm}^{-1}$ and $1493 \mathrm{~cm}^{-1}$ of polycatechol were due to the ortho-disubstitute benzene ring vibrations. In addition, the C-O stretching vibrations for catechol were observed at 1280, 1256 and $1242 \mathrm{~cm}^{-1}$, while the characteristic C-O-C adsorption peak of phenyl ether in polycatechol structure appeared at $1269 \mathrm{~cm}^{-1}$. The intense C-O-C bond absorption for phenyl ether indicated that catechol units in polycatechol structure jointed with each other by ether linkages [35]. Meanwhile, the broad phenolic O-H vibration suggested that there were still a large amount of phenolic $\mathrm{O}-\mathrm{H}$ groups in polycatechol structure. The chemical structure of the enzymatically produced polycatechol was speculated and is presented in Figure 3(a).

(a)

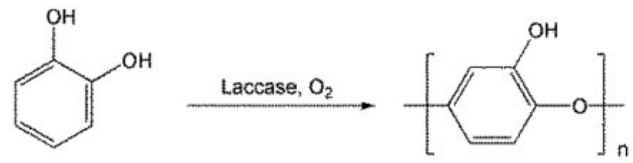

(b)<smiles>Oc1cccc(O)c1</smiles><smiles>CC(C)(C)Cc1c(C(C)(C)C)ccc(O)c1O</smiles>

(c)<smiles>Oc1ccc(O)cc1</smiles>

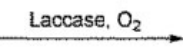<smiles>CC(C)(C)Oc1c(O)cc(C(C)(C)C)cc1O</smiles>

(e)

(d)<smiles>Oc1cccc(O)c1O</smiles><smiles>C[14CH3]</smiles><smiles>CC(C)(C)OCCO</smiles><smiles>CC(C)(C)c1c(O)cc(O)c(C(C)(C)C)c1O</smiles>

Figure 3. The proposed chemical construction of the enzymatically produced phenolic polymers with catechol (a), resorcinol (b), hydroquinone (c), pyrogallol (d) and phloroglucinol (e), respectively. 
For resorcinol, the adsorption bands at $3258 \mathrm{~cm}^{-1}, 1608$ and $1490 \mathrm{~cm}^{-1}$, $1297 \mathrm{~cm}^{-1}$ belonged to the phenolic $\mathrm{O}-\mathrm{H}$ vibration, the aromatic $\mathrm{C}=\mathrm{C}$ vibrations and the phenolic $\mathrm{C}-\mathrm{O}$ vibration, respectively. In comparison, the above IR vibrations of polyresorcinol appeared at 3423,1606 and $1148 \mathrm{~cm}^{-1}$, respectively. No remarkable vibration peaks of phenyl ether bond were observed in the IR spectrum of polyresorcinol. Moreover, the second and fourth aromatic carbons of resorcinol possess high reactivity and always act as initiating sites of corresponding chemical reactions. As supported above, C-C linkage was assumed the binding bond of resorcinol units in polyresorcinol macromolecules (shown in Figure 3b).

For hydroquinone, the peaks at $3262 \mathrm{~cm}^{-1}, 1518$ and $1475 \mathrm{~cm}^{-1}, 1259$ and $1243 \mathrm{~cm}^{-1}$ represented the phenolic $\mathrm{O}-\mathrm{H}$ vibration, the $\mathrm{C}=\mathrm{C}$ vibrations of aromatic rings and the phenolic $\mathrm{C}-\mathrm{O}$ vibrations, respectively. By contrast, the above vibrations of polyhydroquinone emerged at $3416 \mathrm{~cm}^{-1}, 1628$ and $1505 \mathrm{~cm}^{-1}$, $1197 \mathrm{~cm}^{-1}$, respectively. The new bands at 1793 and $1655 \mathrm{~cm}^{-1}$ was corresponding to the $\mathrm{C}=\mathrm{O}$ vibrations of quinones [31]. However, the C-O-C vibration bands of phenyl ether between 1300 and $1200 \mathrm{~cm}^{-1}$ were inconspicuous. As given above, it can be supposed that hydroquinone units in polyhydroquinone structure linked with each other by C-C bonds as shown in Figure 3(c).

For pyrogallol, the bands at $3431 \mathrm{~cm}^{-1}, 1622,1524$ and $1484 \mathrm{~cm}^{-1}, 1288$ and $1244 \mathrm{~cm}^{-1}$ were ascribed to the phenolic O-H vibration, the aromatic skeletal vibrations and the phenolic $\mathrm{C}-\mathrm{O}$ vibrations, respectively. In comparison, the phenolic $\mathrm{O}-\mathrm{H}$ vibration and the aromatic skeletal vibration of polypyrogallol were observed at 3416 and $1597 \mathrm{~cm}^{-1}$, respectively. The characteristic C-O-C stretching vibration for phenyl ether was also seen at $1219 \mathrm{~cm}^{-1}$. The adsorption bands of phenolic hydroxyl group and the phenyl ether bond in polypyrogallol indicated that pyrogallol units in the produced polypyrogallol connected to each other by ether linkages [37] as shown in Figure 3(d).

For phloroglucinol, its characteristic phenolic O-H vibrations were at 3474 and $3204 \mathrm{~cm}^{-1}$. The peaks at 1620,1499 and $1420 \mathrm{~cm}^{-1}$ were attributed to the aromatic skeletal vibrations and the peak at $1300 \mathrm{~cm}^{-1}$ was due to the phenolic C-O vibration. By contrast, the above three adsorptions in polyphloroglucinol appeared at 3428,1631 and $1154 \mathrm{~cm}^{-1}$, respectively. There was no distinct vibration peak from 1300 to $1200 \mathrm{~cm}^{-1}$ representing the C-O-C stretching vibration of phenyl ether. As suggested above, it can be hypothesized that phloroglucinol monomers concatenated to each other by $\mathrm{C}-\mathrm{C}$ linkages after the laccase-mediated oxidative polymerization as shown in Figure 3(e).

\section{XPS analysis of jute fabrics}

XPS was employed to analyze the changes in surface chemistry of jute fabrics after the enzymatic coating with the in-situ-produced polymers of the five polyhydric phenols. Table 1 gives the surface elemental compositions of control, laccase-treated and various coated jute fabric samples. It was found that the $\mathrm{C} / \mathrm{O}$ ratios of the coated jute fabrics were increased when compared with the control and 
Table I. Surface chemical compositions of various jute fabrics obtained by $\mathrm{X}$-ray photoelectron spectroscopy XPS) analysis.

\begin{tabular}{llllll}
\hline & \multicolumn{2}{l}{ Elements (\%) } & & C/O \\
\cline { 2 - 4 } Samples & Cls & OIs & N Is & ratio \\
\hline Control jute & 58.63 & 38.00 & 3.37 & 1.54 \\
Laccase-treated jute & 59.19 & 36.90 & 3.91 & 1.60 \\
Polycatechol-coated jute & 72.55 & 26.54 & 0.91 & 2.73 \\
Polyresorcinol-coated jute & 66.33 & 31.35 & 2.32 & 2.12 \\
Polyhydroquinone-coated jute & 66.28 & 31.35 & 2.37 & 2.11 \\
Polypyrogallol-coated jute & 63.76 & 34.63 & 1.61 & 1.84 \\
Polyphloroglucinol-coated jute & 62.23 & 33.68 & 4.08 & 1.85 \\
\hline
\end{tabular}

laccase-treated one. This is mainly due to the surface covering of polyphenols with high $\mathrm{C} / \mathrm{O}$ ratios. The $\mathrm{C} / \mathrm{O}$ ratios of polycatechol, polyresorcinol and polyhydroquinone were calculated to be 2.25 from the assumed constitutional formulas in Figure 3 and the $\mathrm{C} / \mathrm{O}$ ratios of polypyrogallol and polyphloroglucinol were 1.5. However, some coated jute fabrics showed higher $\mathrm{C} / \mathrm{O}$ ratios than their coating polymers such as polycatechol-coated jute fabric, polypyrogallol-coated jute fabric and polyphloroglucinol-coated jute fabric. This can be explained that the phenolic -OH groups of the in-situ-formed polyphenols were involved into the grafting reaction with lignin on the jute surface and condensed with the ortho-disubstitute phenolic $-\mathrm{OH}$ groups of lignin molecules to form phenyl ethers.

The increase in the nitrogen content of the laccase-treated jute fabric could be attributed to some adsorbed laccase proteins. The nitrogen content of the coated jute fabrics could be the combined contribution of surface coating with nitrogenfree polyphenols and enzyme adsorption. The more the coated polymers on the jute surface, the lower the nitrogen content of jute fabrics is. And the more the adsorbed laccase proteins, the higher the nitrogen content is. The adsorption of laccase proteins on the coated jute surface partly depended on the hydroxyl content of the new surface which is in accordance with the amount and structural property of each coated polyphenol. For catechol, pyrogallol, resorcinol and hydroquinone, the nitrogen contents of jute fabrics coated with their corresponding polymers were lower than that of the control sample, which indicated their surface coating is dominating in the contribution of the nitrogen content. For phloroglucinol, the nitrogen content of the coated jute fabric was higher than that of the laccasetreated sample since the enzyme adsorption took place of the surface coating to be dominant.

In order to obtain the chemical bonding state of carbon atom on the jute fabric surface, the deconvolution of $\mathrm{C}$ 1s high-resolution spectra was carried out by curve fitting. As shown in Figure 4, the C1s spectra were deconvoluted into five peaks of $\mathrm{C} 1, \mathrm{C} 2, \mathrm{C} 3, \mathrm{C} 4$ and $\mathrm{C} 5$. According to the literature [38], the $\mathrm{C} 5$ peak with the 


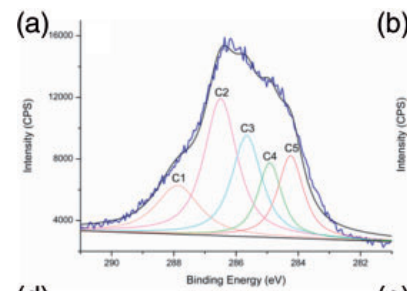

(d)

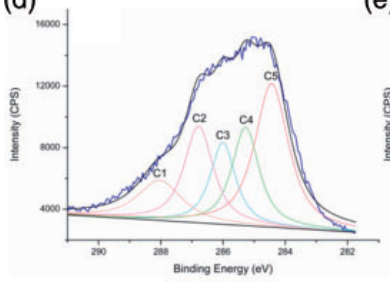

(b)

(e)

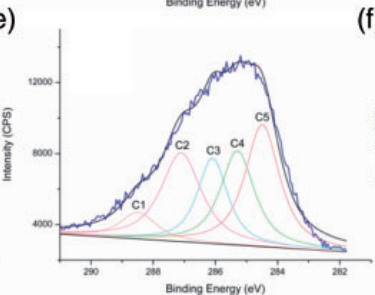

(f)
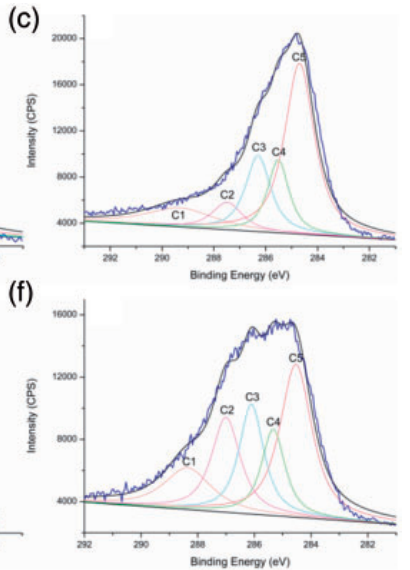

(g)

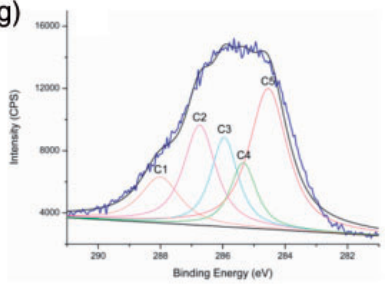

Figure 4. Deconvoluted Cls spectra of control jute (a), laccase-treated jute (b), polycatecholcoated jute (c), polyresorcinol-coated jute (d), polyhydroquinone-coated jute (e), polypyrogallolcoated jute (f) and polyphloroglucinol-coated jute (g).

lowest binding energy originates from a carbon atom bound only to carbon or hydrogen atoms (-C-C/-C-H). The $\mathrm{C} 4$ peak represents a carbon atom linked to an ether oxygen atom (-C-O-C). The $\mathrm{C} 3$ peak corresponds to a carbon atom bound to a hydroxyl oxygen atom (-C-O-H). The $\mathrm{C} 2$ peak represents a carbon atom linked to two non-carbonyl oxygen atoms $(\mathrm{O}-\mathrm{C}-\mathrm{O})$ which only existed in the cellulose of jute fiber. The $\mathrm{C} 1$ peak with the highest binding energy represents a carbon atom bound to one carbonyl oxygen atom $(-\mathrm{C}=\mathrm{O})$ in lignin or pectin. The proportions and the peak assignments of these chemical bonds were presented in Table 2. The laccasetreated jute fabric showed decreasing of $\mathrm{C} 3$ content and increasing of $\mathrm{C} 4$ and $\mathrm{C} 5$ contents, which suggested the transformation of phenolic -OH group to phenyl ether and the formation of $\mathrm{C}-\mathrm{C}$ bond between two aromatic rings after the laccasemediated oxidation of lignin on the jute fabric surface. After the coating treatments, the $\mathrm{C} 2$ contents of the jute fabrics were decreased for the covering of cellulose component on the surface with polyphenols. The more the coated polymers on the jute surface, the lower is the $\mathrm{C} 2$ content of $\mathrm{C} 1 \mathrm{~s}$ spectra. Consequently, the catechol monomer obtained the most coating effect on jute fabrics via the laccase-mediated in-situ oxidative polymerization. The next is pyrogallol, resorcinol, phloroglucinol and hydroquinone in sequence. The C3 and C5 contents of the coated jute fabrics were increased when compared with the laccase-treated jute 


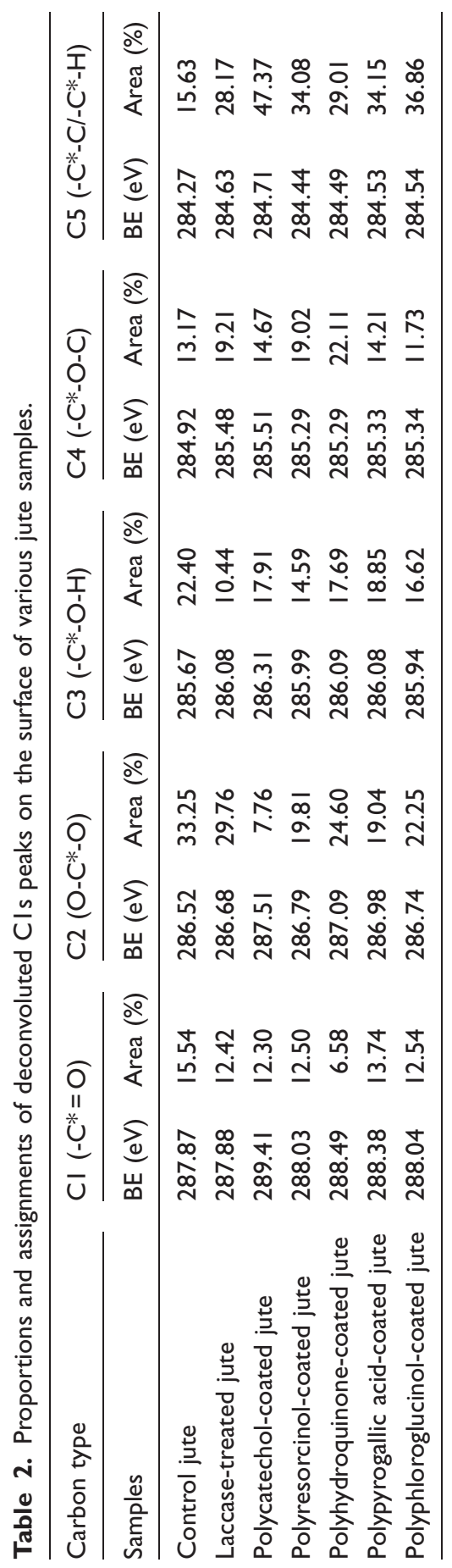


fabrics as a result of the introduction of polyphenols on surfaces. The $\mathrm{C} 4$ proportions of the coated jute fabrics were various. The variations of the $\mathrm{C} 3, \mathrm{C} 4$ and $\mathrm{C} 5$ contents on the jute surface all depended on the coated amount and the structural properties of the adsorbed polyphenols and the grafted ones by condensation with lignin.

\section{SEM analysis of jute fabric surfaces}

The surface morphology of control, laccase-treated and polyphenol-coated jute fabrics was investigated by SEM and is shown in Figure 5. The surface of the control jute was neatly arranged with some natural impurities covered (Figure 5a). After the laccase treatment the jute surface became smooth and glossy (Figure 5b), which is probably owing to the enzymatic dislodgement and redistribution of bulgy lignins on the surface as a result of the laccase-mediated simultaneous degradation and polymerization of lignin [39]. The jute surfaces coated with different polyphenols were rough and irregular with some particulates or flakes contained as shown in Figure 5(c) to (g), respectively. These materials on the enzymatically coated jute surface were considered the homopolymers of the five
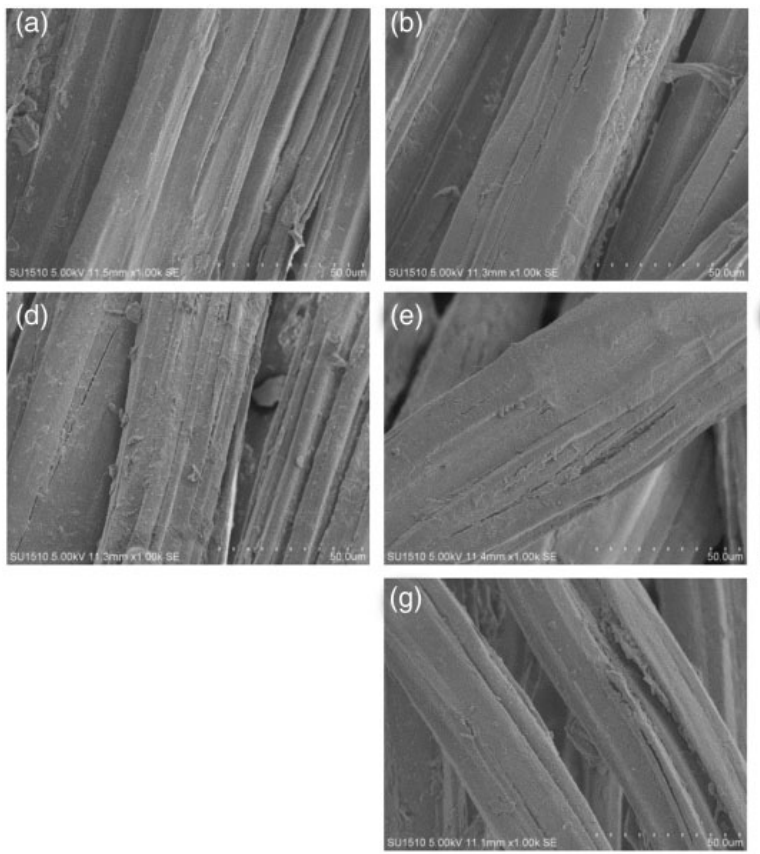
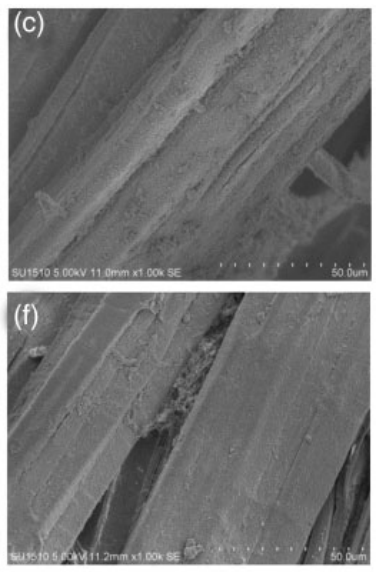

Figure 5. SEM images of control jute fabric (a), laccase-treated jute fabric (b), polycatecholcoated jute (c), polyresorcinol-coated jute (d), polyhydroquinone-coated jute (e), polypyrogallolcoated jute (f) and polyphloroglucinol-coated jute (g) amplified at $1.00 \mathrm{k}$. 
polyhydric phenols and attached by way of covalent grafting and non-specific hydrogen-bonding absorption. Besides, the degree of the enzymatic coating was associated with the monomers used. Jute fabrics coated by the laccase-mediated insitu polymerization of catechol and resorcinol showed more amount of surface coating than those of polypyrogallol, phloroglucinol and hydroquinone, which is approximately in accordance with the conclusion supported by the C2 data of XPS in Table 2.

\section{UV-protective properties of jute fabrics}

The effects of the coating treatments with different polyhydric phenols and the incubation time on the UPF of jute fabrics were investigated as shown in Figure 6. After various coating treatments, the UPF values of jute fabrics were increased with different degrees. The increasing extent in UPF of coated jute fabrics possibly depended not only on the coating amount but also on the chemical structure of the coated polymers. The polymeric structure was bound up with the polymerization characteristics of the phenolic monomers. The coating amount of phenolic polymers on jute fabric surface was affected by the incubation time and the selected phenol. The five polyhydric phenols tested for the enzymatic coating showed different trends in UPF of jute fabrics with the increasing of incubation time. In the enzymatic coating reaction, polymerization and depolymerization of polyhydric phenols occurred simultaneously. At the beginning, the phenolic monomers were polymerized dramatically under the catalysis of laccase. The coating resulted from the covalent coupling/grafting and the non-covalent deposition was also enhanced. In the latter stage of the reaction, the laccase-mediated depolymerization became predominant. The coated polymers started to degrade

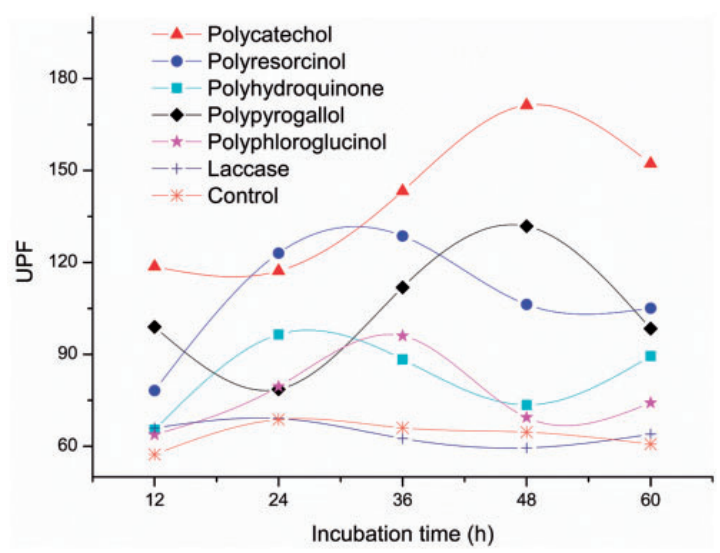

Figure 6. The UPF values of control, laccase-treated and enzymatically coated jute fabrics with various polyhydric phenols in different incubation periods. 


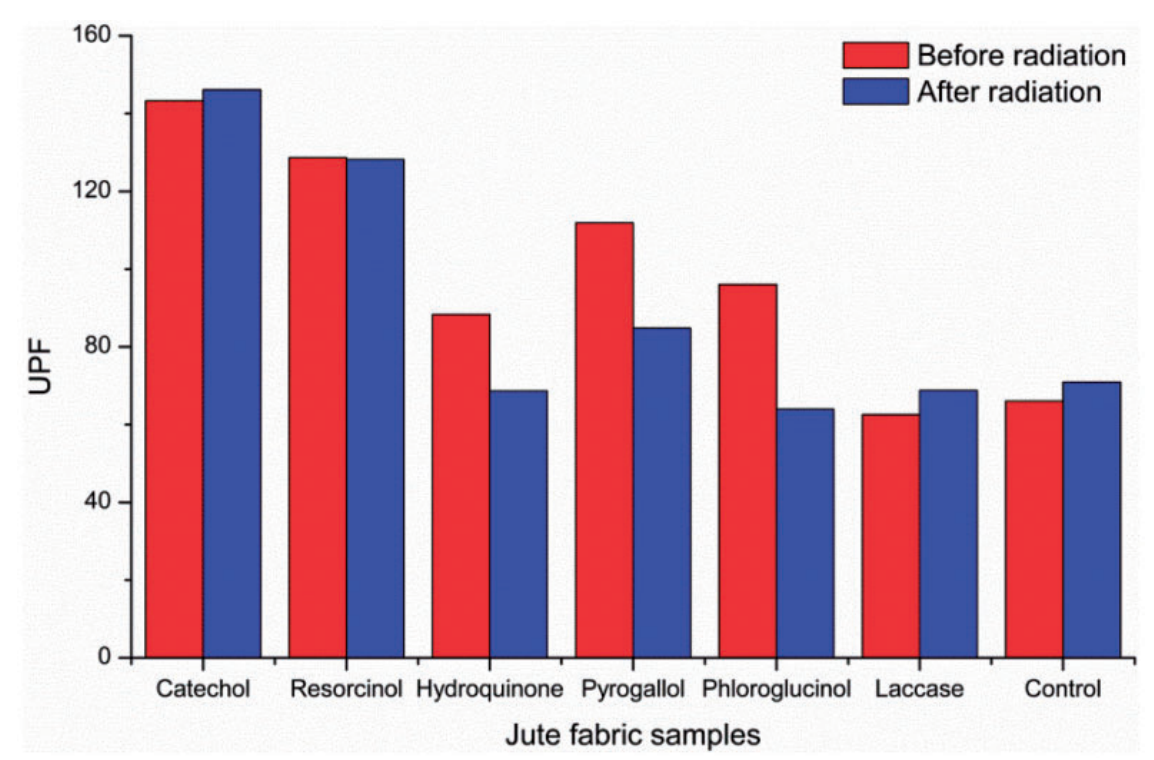

Figure 7. The UPF comparison of various jute fabric samples before and after radiation.

into lower-molecular-weight pieces and fall back to the aqueous medium [39]. The incubation time for different polyhydric phenols to reach their maximum polymerization degree was various. The coating with polycatechol obtained the best UVprotective performance and got its maximum UPF at the incubation time of $48 \mathrm{~h}$. The others were polypyrogallol, polyresorcinol, polyhydroquinone and polyphloroglucinol in order from massive to poor. And their incubation periods for the optimal UPF of jute fabrics were $48 \mathrm{~h}, 36 \mathrm{~h}, 24 \mathrm{~h}$ and $36 \mathrm{~h}$, respectively.

\section{UV resistance of jute fabrics}

As shown in Figure 7, the UV resistance of jute fabrics after various coating treatments was studied as compared with the laccase-treated and control samples. The jute fabrics coated with polycatechol and polyresorcinol exhibited strong UV resistance with no UPF dropped after radiation. However, the UPF values of jute fabrics coated with polyhydroquinone, polypyrogallol and polyphloroglucinol after radiation were declined by $22.35 \%, 24.18 \%$ and $33.40 \%$, respectively. These results indicated that the laccase-induced polymeric structures of catechol and resorcinol in jute fabric coatings were more tolerant for suffering the radiation of UV rays.

\section{Conclusions}

The present work demonstrated that the enzymatic coating via the in-situ polymerization of polyhydric phenols was achieved for enhancing the UV protective 
properties of technical jute fabrics. The units in the polymer of catechol or pyrogallol were connected to each other by ether bonds. However, monomers of resorcinol, hydroquinone and phloroglucinol were polymerized, respectively, by laccase with $\mathrm{C}-\mathrm{C}$ bonds jointed together. The enzymatic coatings of jute fabrics with these polyhydric phenols were confirmed by XPS and SEM. The grafting reaction of polyphenols to lignins on the jute surface was proved to be actually existed and the sequence of the coating amounts varied from different polyhydric phenols. The UV protective performance of jute fabrics after the coating of polyphenols was increased in variety, which depended on the coating amount and the chemical structure of the coated phenolic polymers. The enzymatic coating polymerized with catechol obtained the best anti-UV properties. Besides, different polyhydric phenols used in the enzymatic coating showed various trends in UPF of jute fabrics with the increasing of incubation time. The jute fabrics coated with in-situ generated polycatechols or polyresorcinols presented almost no decrease in UPF after radiation, showing excellent UV aging resistance. The enzymatically coated jute fabrics which were UV-resistant could be utilized in technical textiles outdoors, such as packing bags, ropes and textile coverings to enhance their working life and maintain the mechanical properties for a longer time under sunlight.

\section{Declaration of Conflicting Interests}

The author(s) declared no potential conflicts of interest with respect to the research, authorship, and/or publication of this article.

\section{Funding}

The author(s) disclosed receipt of the following financial support for the research, authorship, and/or publication of this article: This work was financially supported by National Natural Science Foundation of China (51173071), Program for New Century Excellent Talents in University (NCET-12-0883), Program for Changjiang Scholars and Innovative Research Team in University (IRT1135), Fundamental Research Funds for the Central Universities (JUSRP51312B), the Graduate Student Innovation Plan of Jiangsu Province of China (CXZZ13_0752) and the Doctor Candidate Foundation of Jiangnan University of China (JUDCF13023).

\section{References}

[1] Saravanan D. UV protection textile materials. Autex Res $J$ 2007; 7: 53-62.

[2] Das BR. UV radiation protective clothing. Open Text $J$ 2010; 3: 14-21.

[3] Ibrahim NA, Amr A, Eid BM, et al. Poly(acrylic acid)/poly(ethylene glycol) adduct for attaining multifunctional cellulosic fabrics. Carbohyd Polym 2012; 89: 660-684.

[4] Ibrahim NA, Refaie R and Ahmed AF. Novel approach for attaining cotton fabric with multi-functional properties. J Ind Text 2010; 40: 65-83.

[5] Ibrahim NA, El-Zairy EMR, El-Zairy MR, et al. Improving transfer printing and UVblocking properties of polyester of polyester-based textiles using MCT- $\beta C D$, chitosan and ethylendiamine. Color Technol 2010; 126: 330-336.

[6] Ibrahim NA, Eid BM, Hashem MM, et al. Smart options for functional finishing of linen-containing fabrics. $J$ Ind Text 2010; 39: 233-265. 
[7] Val $\mathrm{Y}$, Ioan $\mathrm{N}$ and Chen $\mathrm{Y}$. Thermal insulation properties of cellulosic-based nonwoven composites. $J$ Ind Text 2006; 36: 73-87.

[8] Chattopadhyay BC and Chakravarty S. Application of jute geotextiles as facilitator in drainage. Geotex Geomembranes 2009; 27: 156-161.

[9] Thilagavathi T, Pradeep E, Kannaian T, et al. Development of natural fiber nonwovens for application as car interiors for noise control. J Ind Text 2010; 39: 267-278.

[10] Chattopadhyay SN, Pan NC, Roy AK, et al. Development of natural dyed jute fabric with improved colour yield and UV protection characteristics. J Text I 2013; 104: $808-818$.

[11] Ibrahim NA, Amr A, Eid BM, et al. Innovative multi-functional treatments of lignocellulosic jute fabric. Carbohyd Polym 2010; 82: 1198-1204.

[12] Grifoni D, Bacci L, Lonardo SD, et al. UV protective properties of cotton and flax fabrics dyed with multifunctional plant extracts. Dyes Pigments 2014; 105: 89-96.

[13] Ammayappan L, Nayak LK, Ray DP, et al. Functional finishing of jute textiles - an overview in India. $J$ Nat Fibers 2013; 10: 390-413.

[14] Hüttermann A, Mai C and Kharazipour A. Modification of lignin for the production of new compounded materials. App Microbiol Biotechnol 2001; 55: 387-394.

[15] Nyanhongo GS, Kudanga T, Prasetyo EN, et al. Enzymatic polymer functionalisation: advances in laccase and peroxidase derived lignocellulose functional polymers. $A d v$ Biochem Eng Biotechnol 2011; 125: 47-68.

[16] Kudanga T, Nyanhongo GS, Guebitz GM, et al. Potential applications of laccasemediated coupling and grafting reactions: A review. Enzyme Microb Technol 2011; 48: 195-208.

[17] Kudanga T, Prasetyo EN, Sipilä J, et al. Chemo-enzymatic functionalisation of lignocellulose materials using oxiranes. Process Biochem 2010; 45: 1557-1562.

[18] Kalia S, Thakur K, Kumar A, et al. Laccase-assisted surface functionalization of lignocellulosics. J Mol Catal B-Enzym 2014; 102: 48-58.

[19] Ibrahim NA, El-Hossamy M, Hashem MM, et al. Novel pretreatments processes to promote linen-containing fabrics properties. Carbohyd Polym 2008; 74: 880-891.

[20] Riva S. Laccases: blue enzymes for green chemistry. Trends Biotechnol 2006; 24: 219-226.

[21] Rio JC, Rencoret J, Marques G, et al. Structural characterization of the lignin from jute (Corchorus capsularis) fibers. J Agric Food Chem 2009; 57: 10271-10281.

[22] Lahtinen M, Kruus K, Heinonen P, et al. On the reactions of two fungal laccases differing in their redox potential with lignin model compounds: Products and their rate of formation. J Agric Food Chem 2009; 57: 8357-8365.

[23] Areskogh D, Li J, Gellerstedt G, et al. Investigation of the molecular weight increase of commercial lignosulfonates by laccase catalysis. Biomacromolecules 2010; 11 : 904-910.

[24] Kudanga T, Prasetyo EN, Widsten P, et al. Laccase catalyzed covalent coupling of fluorophenols increases lignocellulose surface hydrophobicity. Bioresour Technol 2010; 101: 2793-2799.

[25] Widsten P, Heathcote C, Kandelbauer A, et al. Enzymatic surface functionalisation of lignocellulosic materials with tannins for enhancing antibacterial properties. Process Biochem 2010; 45: 1072-1081.

[26] Garcia-Ubasart J, Vidal T, Torres AL, et al. Laccase-mediated coupling of nonpolar chains for the hydrophobization of lignocellulose. Biomacromolecules 2013; 14: 1637-1644. 
[27] Reynaud C, Tapin-Lingua S, Elegir G, et al. Hydrophobic properties conferred to Kraft pulp by a laccase-catalysed treatment with lauryl gallate. J Biotechnol 2014; 167: 302-308.

[28] Aracri E, Fillat A, Colom JF, et al. Enzymatic grafting of simple phenols on flax and sisal pulp fibres using laccases. Bioresour Technol 2010; 101: 8211-8216.

[29] Elegir G, Kindl A, Sadocco P, et al. Development of antimicrobial cellulose packaging through laccase-mediated grafting of phenolic compounds. Enzyme Microb Technol 2008; 43: 84-92.

[30] Chandra RP and Ragauskas AJ. Evaluating laccase-facilitated coupling of phenolic acids to high-yield kraft pulps. Enzyme Microb Technol 2002; 30: 855-861.

[31] Uyama $\mathrm{H}$ and Kobayashi S. Enzyme-catalyzed polymerization to functional polymers. J Mol Catal B-Enzym 2002; 19-20: 117-127.

[32] Schroeder M, Aichernig N, Guebitz GM, et al. Enzymatic coating of lignocellulosic surfaces with polyphenols. Biotechnol J 2007; 2: 334-341.

[33] Mai C, Schormann W and Hüttermann A. Chemo-enzymatically induced copolymerization of phenolics with acrylate compounds. Appl Microbiol Biotechnol 2001; 55: $177-186$.

[34] Childs R and Bardsley W. The steady-state kinetics of peroxidase with 2,2'-azino-bis-(3ethylthiazoline-6-sulfonic acid) as chromogen. Biochem $J$ 1975; 145: 93-103.

[35] Aktas N, Sahiner N, Kantoglu O, et al. Biosynthesis and characterization of laccase catalyzed poly(catechol). J Polym Environ 2003; 11: 123-128.

[36] Kim S, Silva C, Zille A, et al. Characterisation of enzymatically oxidized lignosulfonates and their application on lignocellulosic fabrics. Polym Int 2009; 58: 863-868.

[37] Guresir M, Aktas N and Tanyolac A. Influence of reaction conditions on the rate of enzymic polymerization of pyrogallol using laccase. Process Biochem 2005; 40: $1175-1182$.

[38] Kafi AA, Magniez K and Fox BL. A surface-property relationship of atmospheric plasma treated jute composites. Compos Sci Technol 2011; 71: 1692-1698.

[39] Zhou H, Yang D, Wu X, et al. Structure and adsorption characterization of sodium lignosulfonate by laccase modification. Chem J Chinese U 2013; 34: 218-224. 